\title{
RELAÇÕES RACIAIS EM WEBSERIES BRASILEIRAS: PERPETUAÇÃO DE VELHAS HIERARQUIAS RACIAIS NA ERA DA WEB
}

\author{
RACE RELATIONS IN BRAZIL WEB SERIES: PERPETUATING OLD RACIAL \\ HIERARCHIES IN THE WEB ERA
}

\author{
LAS RELACIONES RACIALES EN WEBSERIES DE BRASIL: LA \\ PERPETUACIÓN DE VIEJAS JERARQUÍAS RACIALES EN LA ERA DE LA \\ $W E B$
}

\author{
Wellington Oliveira dos Santos \\ Doutorando da Universidade \\ Ferderal do Paraná - UFPR \\ psicologowell@gmail.com
}

\begin{abstract}
Resumo
O artigo apresenta pesquisa realizada acerca da participação de personagens negros e brancos em webseries brasileiras. Para a análise utilizamos procedimentos de análise crítica do discurso combinados com a interpretação de ideologia de Thompson (1995). Selecionamos webseries que se destacaram no ano de 2011. Os negros estiveram ausentes ou subrepresentados na maioria delas entre os personagens, além de racializados e presos a estereótipos que circulam em outras mídias como a TV. Os personagens brancos foram tratados como representantes da humanidade. Argumentamos que a forma como personagens negros e brancos são apresentados nas webseries decorre da persistência de discursos racistas na mídia nacional.
\end{abstract}

Palavras-chave: Racismo discursivo. Webseries. Mídia.

\begin{abstract}
The article presents research about the participation of black and white characters in Brazilian web series. For the analysis procedures used critical discourse analysis combined with the interpretation of ideology Thompson (1995). Selected web series that stood out in 2011. Blacks were underrepresented or absent in most of them between the characters, as well as inmates and racialized stereotypes that circulate in other media like TV. The white characters were treated as representatives of humanity. We argue that the way black and white characters are displayed in the web series follows the persistence of racist discourse in the national media.
\end{abstract}

Key-words: Discursive racism. Webseries. Media. 


\section{Resumen}

El artículo presenta una investigación sobre la participación de personajes blancos y negros en las webserie de Brasil. Para los procedimientos de análisis utilizados análisis crítico del discurso junto con la interpretación de la ideología Thompson (1995). Seleccionado webseries que se destacaron en el año 2011. Los negros estaban poco representados o ausente de la mayoría de ellos entre los personajes, así como de los internos y los estereotipos racistas que circulan en otros medios como la televisión. Los personajes blancos fueron tratados como representantes de la humanidad. Nosotros sostenemos que la forma en caracteres blancos y negros se muestran en las webseries sigue la persistencia del discurso racista en los medios de comunicación nacionales.

Palabras clave: Racismo discursivo. Webseries. Médios de comunicación.

\section{INTRODUÇÃO}

Analisamos a presença de personagens negros e brancos em webseries brasileiras a partir da proposta teórica de ideologia de John Thompson (1995) com o objetivo de verificar os espaços ocupados por esses grupos étnico-raciais.

Nas duas primeiras décadas do século XXI assistimos a uma movimentação intensa de diversos atores sociais em torno da questão da diversidade étnico racial brasileira. Essa movimentação resulta, entre outras coisas, das reivindicações do movimento negro e de pesquisas divulgadas que destacaram desigualdades extremas entre os grupos raciais branco e negro no Brasil. Como consequência, o Estado brasileiro foi pressionado para tomar medidas consideradas antirracistas, tais como a modificação da Lei de Diretrizes e Bases da Educação (LDB) com a lei 10.639/03 que introduz o ensino de história e cultura afro-brasileira nas escolas de ensino básico.

Nesse contexto sócio-histórico, uma cobrança tem sido feita quanto ao papel da mídia na criação do imaginário social acerca das relações raciais brasileiras. Desde o inicio do século XX o movimento negro tem feito, entre suas reivindicações perante o Estado, propostas de modificação da representação do negro tanto na educação quanto nas produções simbólicas (SILVA Jr, 1997, apud ARAÚJO, 2000). A cobrança tem sentido, se considerarmos estudos que apontam que os negros estão ausentes de diversas produções simbólicas brasileiras, tanto como produtores dessas produções como entre os personagens (SILVA; ROSEMBERG, 2008). 
O que argumentamos neste texto é que a categoria teórica ideologia, conforme proposta por Thompson (1995) pode ser um instrumento de denúncia de desigualdades raciais entre negros e brancos nas recentes produções simbólicas brasileiras que circulam na internet. Apresentamos, então, como aplicamos esse conceito em estudo acerca das relações raciais em uma das produções simbólicas da internet: as webseries.

\section{IDEOLOGIA E ANÁLISE DE FORMAS SIMBÓLICAS}

Neste texto, tomamos as webseries como formas simbólicas capazes de atuar, em contextos sócio-históricos específicos, de maneira a criar ou sustentar relações de dominação, conforme a proposta de Thompson (1995). Para Thompson, nas sociedades modernas as formas simbólicas difundidas em larga escala, como as webseries, tem um papel fundamental na manutenção de desigualdades de acesso a bens materiais e simbólicos. Elas podem ser usadas para manter e criar relações de dominação entre indivíduos ou grupos de indivíduos. Nesse caso, essas formas simbólicas estariam atuando de maneira ideológica ${ }^{1}$ ou, em outras palavras, a serviço do poder. Poder, aqui, é acesso a bens materiais e simbólicos. Formas simbólicas são falas, ações, imagens, sons, escritas, etc. que são produzidos por sujeitos e reconhecidos por eles e outros como construtos significativos (THOMPSON, 1995). Quando discute o papel das formas simbólicas nas sociedades contemporâneas, Thompson (1995) está interessado em como elas podem atuar de maneira ideológica; isto é, servindo em circunstâncias sócio-históricas específicas para estabelecer e sustentar relações de dominação. Relações de dominação não se restringem ou se submetem as relações do capitalismo: as desigualdades assimétricas podem ser baseadas em critérios raciais, sexuais, culturais, entre outros.

Thompson (1995) apresenta modos gerais de operação da ideologia; modos como o sentido pode servir para estabelecer e sustentar relações de dominação em contextos sóciohistóricos específicos, sintetizados no quadro a seguir (QUADRO 1). Ao atentarmos para os modos gerais, verificamos que o conceito de ideologia em Thompson é um conceito prático, ou seja, ideologia é uma prática que serve para criar ou manter relações assimétricas desiguais, como afirma Guareschi (2000).

\footnotetext{
${ }^{1}$ Devido as limitações do artigo, não realizamos aqui uma discussão mais profunda dos diversos usos do conceito de ideologia nas ciências sociais e humanas. Recomendamos leitura do texto do próprio Thompson (1995).
} 
Quadro 1 - Modos gerais e estratégias de operação da ideologia

\begin{tabular}{|l|l|}
\hline Modos Gerais & Estratégias típicas de construção simbólica \\
\hline Legitimação & - Racionalização \\
& - Universalização \\
& - Narrativização \\
\hline Dissimulação & - Deslocamento: \\
& - Eufemização \\
& - Tropo \\
& - Sinédoque \\
& - Metonímia \\
& - Metáfora \\
& - Silêncio \\
\hline Unificação & - Padronização \\
& - Simbolização da unidade. \\
\hline Fragmentação & - Diferenciação \\
& - Expurgo do outro \\
& - Estigmatização \\
\hline Reificação & - Naturalização. \\
& - Eternalização \\
& - Nominalização \\
& - Passifização \\
\hline \multirow{3}{*}{ Banalização } & - Divertimento \\
& - Fait-Divers \\
& - Ironia \\
\hline
\end{tabular}

Fonte: Adaptado de Thompson (1995, p. 80-89), com aportes de Guareschi (2000, p.317-338), Andrade (2004, p.107-108) e Silva (2008).

Nota: Como forma de ajudar na diferenciação de modos gerais e estratégias típicas adotamos como forma de destaque no QUADRO 1 e no decorrer do texto, o negrito para os modos gerais de operação da ideologia e o itálico para as estratégias típicas.

Tais modos não são os únicos modos que a ideologia pode operar, e nem sempre operam independentemente um do outro. Circunstâncias concretas é que indicam os usos ideológicos das formas simbólicas.

Thompson (1995) propõe uma metodologia para a interpretação das formas simbólicas: a Hermenêutica de Profundidade (HP). Ela pode ser utilizada para analisarmos formas simbólicas em geral ou fatos comunicacionais quaisquer (GUARESCHI, 2000).

O mundo sócio-histórico é um mundo pré-interpretado, o que significa dizer que a interpretação do analista será uma reinterpretação das formas simbólicas (mesmo porque o próprio analista faz parte desse mundo sócio-histórico). Na pesquisa social, os resultados podem ser apropriados pelos sujeitos; sujeitos esses que são ativos nos contextos sociais. Nesse sentido, as interpretações do analista podem atuar de modo a denunciar desigualdades existentes entre grupos sociais (THOMPSON, 1995). 
O mundo social é um campo de força, poder e conflito. O ponto de partida da HP é a interpretação da Doxa (hermenêutica da vida quotidiana): interpretação das opiniões, crenças e entendimentos que são sustentadas e partilhadas pelas pessoas que constituem o mundo social. Para Guareschi (2000), a interpretação da Doxa é uma interpretação de superfície, porque a análise não se estende além do próprio fenômeno. É preciso então levar em consideração outros aspectos das formas simbólicas, aspectos esses que a HP pode auxiliar a desvendar em suas fases.

A Hermenêutica de Profundidade é composta de três fases ou procedimentos principais:

1) Análise sócio-histórica, que consiste na análise dos contextos sócio-históricos específicos de produção e recepção das formas simbólicas. De acordo com Guareschi, uma pergunta inicial que pode ser feita nessa fase do estudo das formas simbólicas é a seguinte: “ $\mathrm{O}$ que têm a ver o espaço e o tempo com o fenômeno a ser estudado?” (2000, p.83, destaque no original). Também é preciso atentar para os campos de interação existentes entre os sujeitos e/ou os grupos; as instituições sociais que podem intervir ou influenciar os fenômenos em análise; a estrutura social, ou seja, as diversas estruturas que compõem a sociedade; e os meios técnicos de transmissão das formas simbólicas. Neste texto, a análise sócio-histórica destaca as webseries e as desigualdades existentes entre negros e brancos na mídia.

2) Análise formal ou discursiva (análise da organização interna das formas simbólicas). Esse é o momento em que os estudiosos das formas simbólicas tentam se concentrar apenas nas formas simbólicas enquanto tais, sem recorrer aos contextos de produção e circulação (GUARESCHI, 2000).

Para a análise formal, acessamos o site de compartilhamento de vídeos, Youtube ${ }^{2}$, durante o mês de abril de 2012. Analisamos os episódios de cada webserie, buscando apreender os papéis e lugares ocupados por personagens negros e brancos. Algumas questões nortearam nossa análise das personagens, tais como: os vídeos apresentam personagens negros e brancos na mesma proporção? Que papéis ocupam tais personagens? Qual a importância deles para os enredos das webseries que participam?

3) Interpretação/reinterpretação das formas simbólicas. A interpretação consiste em relacionar os dados obtidos na análise das formas simbólicas com os dados obtidos na análise

\footnotetext{
${ }^{2}$ Youtube foi criado em 2005, e permite que seus usuários carreguem e compartilhem seus próprios vídeos em formato digital de maneira gratuita. O nome sugere que quem pode faz o produto cultural (o vídeo digital) é qualquer pessoa que acessar o site, ou seja, você. (Disponível em http://pt.wikipedia.org/wiki/YouTube acesso em 27 de abril de 2012).
} 
do contexto sócio-histórico mostrando como o sentido das formas simbólicas pode servir para criar e manter relações de dominação. Interpretar as formas simbólicas é "explicitar $a$ conexão entre o sentido mobilizado pelas formas simbólicas e as relações de dominação que este sentido ajuda a estabelecer e sustentar” (THOMPSON, 1995, p.379, destaque no original). Acaso a análise fosse restrita à análise formal das formas simbólicas utilizando a análise do conteúdo ou outra ferramenta, p. ex., poderíamos cair na falácia do internalismo (THOMPSON, 1995), isto é, inferir as consequências das formas simbólicas na vida das pessoas apoiados apenas nas formas simbólicas.

Há um risco na interpretação de formas simbólicas que já são, de certo modo, interpretadas pelos sujeitos: ela pode gerar mal estar e conflitos. Thompson (1995) aponta que é justamente nesse ponto que a interpretação pode ter um potencial crítico. Interpretar não é impor uma verdade e sim apresentar um significado possível, que pode ser aceito ou não pelos sujeitos inseridos em diversos contextos. A discussão entre interpretações pode levar a uma reflexão crítica sobre as relações de dominação em que os sujeitos estão inseridos.

\section{NEGROS E BRANCOS NA MÍDIA BRASILEIRA: ALGUMAS CONSIDERAÇÕES}

Neste tópico o objetivo é apresentar alguns lugares comuns de negros e brancos na mídia brasileira, apontados por alguns estudos.

De acordo com a revisão de literatura sobre relações raciais na mídia brasileira, efetuada por Silva e Rosemberg (2008), diversas pesquisas vêm destacando estarem os negros ausentes ou sub-representados em discursos da mídia do Brasil. Realizando revisão de literatura sobre o discurso racial na mídia brasileira (analisando pesquisas nos campos da literatura e cinema, imprensa, televisão, literatura infanto-juvenil e livro didático), os autores sintetizaram os resultados encontrados em quatro pontos: 1) a evidente sub-representação do negro nas diversas mídias; 2) o constante silenciamento das mídias sobre as desigualdades raciais, exercendo um duplo papel: negar os processos de discriminação racial, buscando ocultar a racialização das relações sociais, ao mesmo tempo em que propõe uma homogeneidade cultural ao brasileiro; 3) o branco é tratado como representante "natural” da espécie humana (aqui os autores usam o conceito de branquidade normativa, conforme a proposta de GIROUX, 1999); 4) a estereotipia na representação do homem e da mulher negra, adulto ou criança é recorrentemente assinalada nas diversas mídias.

O racismo brasileiro utiliza, entre outras coisas, o discurso das produções simbólicas para manter-se. Os discursos são produtores e reprodutores de desigualdades em diferentes 
eixos (THOMPSON, 1995), em específico de raça (foco desse estudo, mas sem desconsiderar outros eixos de desigualdade, em especial de idade e gênero). Para Thompson (1995), produções simbólicas de uma sociedade são ideológicas quando atuam de modo a criar ou manter relações de dominação de indivíduos sobre outros, possibilitando acesso a bens materiais e culturais. As desigualdades relativas aos bens simbólicos se relacionam de forma complexa e assíncrona com as desigualdades relativas aos bens materiais, principalmente nas sociedades modernas, onde os discursos midiáticos ocupam especial espaço de estruturação das relações de dominação (THOMPSON, 1995). Acreditamos que esse conceito é útil para a interpretação das relações raciais na mídia nacional porque partimos do pressuposto que a mídia, produção simbólica, pode estar a serviço de determinados grupos sociais e raciais.

Mas como opera o racismo brasileiro que perpassa o discurso midiático? Na visão de Guimarães (1997), a sociedade brasileira é uma sociedade de status onde certos grupos sociais teriam “direitos” a certos privilégios em relação ao Estado e a outros grupos sociais. Esses privilégios seriam garantidos pela aparência e pela cor, considerados pelo teórico os principais (mas não únicos) marcos sociais. Os traços fenotípicos serviriam para indicar certa "essência" dos indivíduos, e não a ascendência. No caráter essencialista da exclusão no Brasil, indivíduos de cor escura e traços ditos "negroides” estariam condenados a ocupar as esferas sociais de baixo status (GUIMARÃES, 1997). Entretanto isso não se daria do mesmo modo em toda parte.

De acordo com Telles (2003) as relações entre os diferentes grupos raciais brasileiros ocorrem de duas formas básicas, conforme o contexto: a horizontal e a vertical. Relações horizontais seriam aquelas em que não haveria qualquer tipo de hierarquia entre os indivíduos participantes, como p. ex. uma partida de futebol entre funcionários de uma empresa. Nessas relações o racismo para com os negros dificilmente se manifestaria. No caso das relações verticais, são as que as hierarquias existentes entre os indivíduos são justificadas ou criadas apelando-se para a raça. Nesse ponto podemos falar que o racismo brasileiro é um racismo de competição, conforme Santos (1984). Utilizando o exemplo dos funcionários, o racismo teria o potencial de se manifestar de forma mais explicita quando eles disputassem uma promoção dentro da empresa. Guimarães (1997) diz que o que torna um indivíduo objeto de preconceito não é tanto a sua ascendência, mas sim a sua aparência física (cor da pele, formato do nariz e lábios e textura do cabelo, principalmente). Mesmo as desigualdades de classe se legitimariam através da ordem de status: seria “normal” encontrarmos boa parte do grupo negro nas camadas sociais mais baixas, pois são cidadãos de baixo status, enquanto as camadas mais 
altas possuem maioria esmagadora de brancos. O curioso é que esse processo, esse racismo, se daria de modo “cordial”, pois não existem mecanismos legais de segregação racial, como os que existiram nos Estados Unidos e na África do Sul p. ex.

Voltando as pesquisas com a mídia, Araújo explica a pouca presença da população negra na televisão brasileira, um dos meios de comunicação de produções simbólicas mais disseminados, da seguinte forma:

O desinteresse histórico da elite brasileira em formar um mercado consumidor amplo e a preferência pela imigração da mão-de-obra européia no período final da escravidão ainda se refletem, atualmente, na atitude de empresários, publicitários e produtores de TV, na escolha dos modelos publicitários, na estética da propaganda e nas dificuldades de apoio financeiro e de incentivo cultural aos programas de TV voltados para a população afro-brasileira. O empresário brasileiro, em sua grande maioria, não acredita que o negro seja uma força econômica. Na lógica desta maioria, preto é igual a pobre, que é igual a consumo de subsistência (2000, p.77).

Além de igualar o negro ao miserável ou subalterno na sociedade, Araújo destaca que a mídia televisiva nacional costuma também apresentar um Brasil de imensa maioria branca, em um exemplo de estética ariana, conceito que ele utiliza para descrever a supervalorização de traços de personagens brancos em detrimento dos traços de personagens negros. Paradoxalmente, ao mesmo tempo em que embranquece a população brasileira, a televisão costuma tratar as relações raciais entre brancos e não brancos como se o Brasil vivesse em uma democracia racial - isto é, como se todas as raças tivessem oportunidades iguais aqui.

Ao falar das telenovelas, principal produto da indústria cultural do Brasil, uma vez que as telenovelas brasileiras são vendidas para vários países do mundo, Araújo (2000) destaca que a maior parte dos personagens negros nas primeiras décadas das telenovelas (que teve inicio em 1951) foi condenada a ocupar estereótipos da época dos romances folhetinescos da escravatura, tais como o do negro humilde, a escrava imoral, o escravo demoníaco (quilombola selvagem), o escravo mau, a mulata sedutora e o mulato desequilibrado. Após a década de 1980, algumas imagens mais positivas passaram a coexistir com tais estereótipos, como a do "[negros] portadores da ginga do balanceado, da alegria, do liberalismo sexual ou como bons de bola - mas que foram sendo desapropriadas, ao longo do século [XX], como características da cultura negra para se tornar patrimônio imaginário da cultura brasileira como um todo, virando um jeito de ser e de definir o brasileiro”.(p.79). Os atores negros protestavam contra os papéis que ocupavam nas telenovelas, entretanto muitas vezes não 
tinham opção outra que não aceitar papéis subalternos tais como de empregada doméstica ou de segurança.

Até o ano 2000 apenas quatro famílias negras de classe média foram apresentadas em telenovelas nacionais. No caso dos comerciais de televisão, a primeira família negra de classe média somente seria apresentada em 1997 em, um comercial de ovos de chocolate da Lacta na páscoa. A publicidade passou a dar uma abertura maior a personagens negros quando pesquisas indicaram o potencial consumidor do negro brasileiro. Já nos telejornais, mantêm-se a tendência a apresentar o negro como pobre, favelado, na violência, e nas drogas.

Diante desse quadro, o movimento negro bem como pesquisadores tem pensando em maneiras de tornar a mídia nacional mais representativa da diversidade. Uma delas é pelo estabelecimento de leis. Nas legislações, p. ex., iniciou-se um processo nos anos 1990 de aprovação de leis orgânicas nos municípios de Goiânia, Vitória, Belo Horizonte, Aracaju e Rio de Janeiro, de artigos nas constituições estaduais do Rio de Janeiro, Bahia, Mato Grosso e Pará, de mudanças na Constituição Federal (Lei n. 9559 de 13 de maio de 1997) chegando às proposições do Estatuto da Igualdade Racial (discussão mais aprofundada consta em SILVA; SANTOS; ROCHA, 2010), com estabelecimento de normas sobre a representação na mídia da diversidade étnico-racial do país, via de regra passando por determinações de que a publicidade dos diferentes entes da federação passassem a cumprir determinados parâmetros. O Estatuto, na primeira versão apresentada em 2000 (Projeto de Lei 3.198/00), previa percentual mínimo de $40 \%$ de afrodescendentes na publicidade. No substitutivo apresentado em 2006 pelo próprio autor (Senador Paulo Paim) previa mínimo de 20\% para toda a publicidade veiculada em televisão e cinema e toda publicidade governamental, sendo pelo menos metade de mulheres negras. No texto aprovado, Lei 12.288 de 20 de julho de 2010, mantiveram-se alguns artigos sobre os meios de comunicação, mas as cotas percentuais foram retiradas do texto da lei:

\section{DOS MEIOS DE COMUNICAÇÃO}

Art. 43. A produção veiculada pelos órgãos de comunicação valorizará a herança cultural e a participação da população negra na história do País.

Art. 44. Na produção de filmes e programas destinados à veiculação pelas emissoras de televisão e em salas cinematográficas, deverá ser adotada a prática de conferir oportunidades de emprego para atores, figurantes e técnicos negros, sendo vedada toda e qualquer discriminação de natureza política, ideológica, étnica ou artística.

Parágrafo único. A exigência disposta no caput não se aplica aos filmes e programas que abordem especificidades de grupos étnicos determinados. 
Art. 45. Aplica-se à produção de peças publicitárias destinadas à veiculação pelas emissoras de televisão e em salas cinematográficas o disposto no art. 44.

Art. 46. Os órgãos e entidades da administração pública federal direta, autárquica ou fundacional, as empresas públicas e as sociedades de economia mista federais deverão incluir cláusulas de participação de artistas negros nos contratos de realização de filmes, programas ou quaisquer outras peças de caráter publicitário.

$\S 1^{0}$ Os órgãos e entidades de que trata este artigo incluirão, nas especificações para contratação de serviços de consultoria, conceituação, produção e realização de filmes, programas ou peças publicitárias, a obrigatoriedade da prática de iguais oportunidades de emprego para as pessoas relacionadas com o projeto ou serviço contratado. (BRASIL, 2010).

Por um lado a Lei apresenta redação um tanto genérica e o não estabelecimento de percentuais (mais a abertura para representação de especificidades de grupos étnicos determinados) atua de forma a que o papel indutor do Estado perca em força e possa ser escamoteado mais facilmente. Por outro a Lei cita especificamente a população negra em dois artigos, pontos que podem ser utilizados como balizadores de pressão social por movimentos sociais, inclusive com possíveis demandas ao judiciário.

É nesse contexto sócio-histórico de desigualdades de representação dos grupos raciais negro e branco nas diferentes mídias, protesto de atores e do movimento e de tentativas de legislar sobre o assunto que surgem as webseries. Antes de passarmos a análise de algumas webseries, fazemos adiante uma pequena discussão desse tipo de produção simbólica, que assim como a discussão acerca de relações raciais na mídia faz parte de nossa investigação do contexto sócio-histórico de circulação dos produtos simbólicos.

\section{AS WEBSERIES COMO PRODUÇÕES SIMBÓLICAS}

Nossa análise de relações raciais em webseries pode ser considerada um estudo exploratório. Tais produtos simbólicos são recentes ${ }^{3}$, e no Brasil começaram com o boom da banda larga aqui, que ocorre somente nos anos $2000^{4}$. Por essa razão, uma definição do termo pode parecer simplista, porém necessária.

Consideramos webserie produções em vídeo disponibilizadas na web (por isso o nome) de curta duração, que narram uma história - fictícia ou não e, assim como as séries de televisão, são segmentadas em episódios e temporadas. Webseries podem falar de comédia, de

\footnotetext{
3 A primeira webserie foi feita nos Estados Unidos, em 1995: The Spot. Informação disponível em http://pt.wikipedia.org/wiki/Webs\%C3\%A9rie acesso em 27 de abril de 2012.

4 Segundo o IBOPE, em 2011 77,8 milhões de pessoas tinham alguma forma de acesso à internet no Brasil, seja em domicílios, locais de trabalho, escolas, lan houses ou outros. (disponível em http://www.ibope.com.br/calandraWeb/servlet/CalandraRedirect?temp=6\&proj=PortalIBOPE\&pub=T\&nome=home_materia $\& d b=c a l d b \& d o c i d=C 2 A 2 C A E 41 B 62 E 75 E 83257907000 E C 04 F$ acesso em 27 de abril de 2012).
} 
drama, de assuntos do cotidiano, etc.. Os episódios, em geral, não passam de dez minutos de duração, o que as aproxima dos sitcoms conforme a sugestão de Messa (2006), que tem episódios de curta duração; ainda assim, segundo a definição da mesma autora, poderíamos dizer que as webseries são herdeiras das séries da televisão, já que tem uma história definida que se desenvolve até um final estabelecido. A conexão entre os episódios, diferentemente das sitcoms cujos episódios podem ser vistos individualmente, torna o comprometimento dos espectadores com as series maior. De acordo com Messa: “[...] há um comprometimento do espectador com o produto midiático, já que elas são apresentadas em capítulos, impondo certo acompanhamento da história apresentada. E, a partir do momento que há comprometimento, há envolvimento.” (MESSA, 2006, p.6).

O comprometimento do público com as webseries precisa ocorrer já nos primeiros minutos do primeiro capítulo, uma vez que os episódios são de curta duração. Essa duração resulta da própria lógica de nossa época de conectados a internet: diante de um computador, telefone celular ou mesmo os chamados tablets, os usuários (internautas) geralmente saltam de uma janela para outra, visitando um grande número de sites em pouco tempo. Conseguir a atenção de usuários cada vez mais exigentes e com cada vez menos tempo, em nossa condição pós-moderna de diminuição do espaço-tempo (HARVEY, 1993), é uma tarefa cada vez mais difícil.

Essas webseries estão disponíveis em sites de compartilhamento de vídeos, tais como o Youtube. De acordo com Araújo e Costa (2009) os sites de hospedagem de vídeos, como o Youtube, possibilitaram não apenas compartilhar produções simbólicas criadas pela grande mídia, mas também aos usuários que criassem suas próprias produções simbólicas. Essa é uma característica da Web $2.0^{5}$ que parece ir ao encontro do lema punk "faça você mesmo" (Do It yourserf). Nos dias atuais os usuários podem criar seus próprios vídeos, seus textos (compartilhar em blogs), opinar em noticiais, criar enciclopédias (a Wikipédia é o maior exemplo atual) e até mesmo recriar suas identidades em sites de relacionamento como o Facebook.

Podemos dizer que as webseries estariam na convergência da internet com a televisão; de fato, pelo menos até o momento, elas resultam da mescla da velocidade da internet com as séries e sitcoms que existem na televisão há décadas. Mas também resultam de uma cultura de convergência porque estão disponíveis em sites de compartilhamento e armazenagem de

\footnotetext{
${ }^{5}$ Primo (2007, apud GIACOMINI, 2011) caracteriza a Web 2.0 como a segunda geração de serviços online, que amplia as formas de compartilhamento e organização de informações, com importantes repercussões sociais. No entanto, alguns especialistas em web criticam esse termo, classificado-o como uma jogada de marketing.
} 
vídeos que rompem com a separação existente entre produtores e consumidores de mídia (JENKINS, 2009, p.29). Nessa lógica, os espectadores podem criar seus próprios produtos e colocá-los a disposição de outras pessoas.

Escolhemos três webseries brasileiras para analise de relações raciais. São elas: “3\%”, “Heróis” e "Lado Nix”. A opção por essas webseries foi porque elas ganharam destaque na mídia com a indicação da Music Televison Brasil (MTV) de melhores webseries brasileiras de $2011^{6}$. A característica em comum da maioria das webseries escolhidas pela MTV é que, se por um lado foram criadas para serem veiculadas em sites de compartilhamento de vídeos da internet, por outro lado seus criadores almejam torná-las produtos da televisão, seja em canais abertos ou na TV a cabo.

\section{NEGROS E BRANCOS: QUE ESPAÇOS OCUPAM NAS WEBSERIES BRASILEIRAS?}

A webserie 3\%, criada por Pedro Aguilera e com direção de Daina Giannecchini, Dani Libardi e Jotagá Crema, com a produção de Maria Bonita Filmes, se passa em uma distopia. A história é narrada em primeira pessoa pela protagonista Bruna, jovem branca, primeira personagem a aparecer no vídeo. Ela conta que vive em um mundo dividido em dois lados: o lado bom e o lado ruim, e que ela nasceu no lado ruim, com muita gente e poucos recursos. Existe um processo de seleção para que as pessoas que estão no lado ruim tenham a oportunidade de passar para o lado bom do mundo.

Em um local semelhante a uma instalação militar, com paredes cinzas, muros altos e seguranças uniformizados, Bruna e outras pessoas são conduzidas a área de seleção de candidatos. O primeiro personagem a falar com ela é um guarda negro, que a apressa a entrar no prédio. O guarda é apresentado de costas, e não ficamos sabendo seu nome. Dentro do prédio, o mesmo guarda negro passa por ela, joga peças de roupas em suas mãos e diz: "Você tem um minuto”. A cena apresenta outras pessoas trocando suas roupas por uniformes cinzas, incluindo um jovem branco em uma cadeira de rodas, Fernando.

A outra personagem feminina da série, Michele, jovem branca, ajuda Bruna a se trocar. Em seguida Bruna reconhece um rapaz branco e o chama de Tiago. O rapaz, no

\footnotetext{
${ }^{6}$ A MTV indicou outras duas webseries além das citadas: “O Demônio não sabe brincar” e “\#E_vc?”. Entendemos que ao escolher as indicadas por esse veículo midiático (a MTV), corremos o risco de ajudar na legitimação deste como especialista em dizer o que tem qualidade e o que não tem no campo das webseries. Ainda assim optamos pela lista da MTV porque entendemos que uma premiação também pode atuar para incentivar na consolidação das webseries nacionais.
} 
entanto, ignora. Na sequencia um segurança, homem branco, explica a multidão de jovens que aos vinte anos eles tem a oportunidade de passar para o lado de lá.

Os quatro personagens vão uma entrevista individual com os entrevistadores. São quatro entrevistadores, todos brancos. A entrevista de seleção para outro mundo mais parece uma entrevista de seleção para um emprego, sendo que os entrevistadores agem como os especialistas de recursos humanos da sociedade atual. Considerando a idade das personagens da webserie, a metáfora faz todo sentido: apresenta jovens assustados em entrevistas com a esperança de ingresso em um mundo melhor (o mercado de trabalho).

Os entrevistadores são retratados como extremamente burocráticos e com abuso de poder. A mulher branca que entrevista Fernando avisa que eles não têm nenhuma política de inclusão para deficientes. O homem branco que entrevista Michele brinca com ela, chamando o namorado dela que tempos antes conseguiu passar pelo processo e agora é funcionário. A mulher que entrevista Tiago pede para ele escolher entre salvar três candidatos que viriam depois dele ou se salva, e ele escolhe a segunda opção. No caso de Bruna, o entrevistador se mostra impaciente e a reprova após ela não conseguir assinar com a caneta seu nome na ficha. Bruna entra em desespero e é presa.

O mesmo guarda negro que aparece no inicio da série organiza os grupos que disputam a segunda etapa do processo. Continuando na metáfora do mundo do trabalho, os personagens na segunda etapa participam de uma dinâmica de grupo em que devem montar no menor tempo possível o maior número de cubos de papel.

O segundo personagem negro que aparece com ação relevante na webserie é uma mulher negra, que está na equipe rival da equipe de Michele e Fernando. Ela não tem qualquer fala.

Na sala de Tiago, em uma disputa por um dos cubos (em que Tiago rouba um cubo da outra equipe), o guarda negro intervém apontando uma pistola para o rapaz branco que agride Tiago. Tiago e sua equipe conseguem passar. 


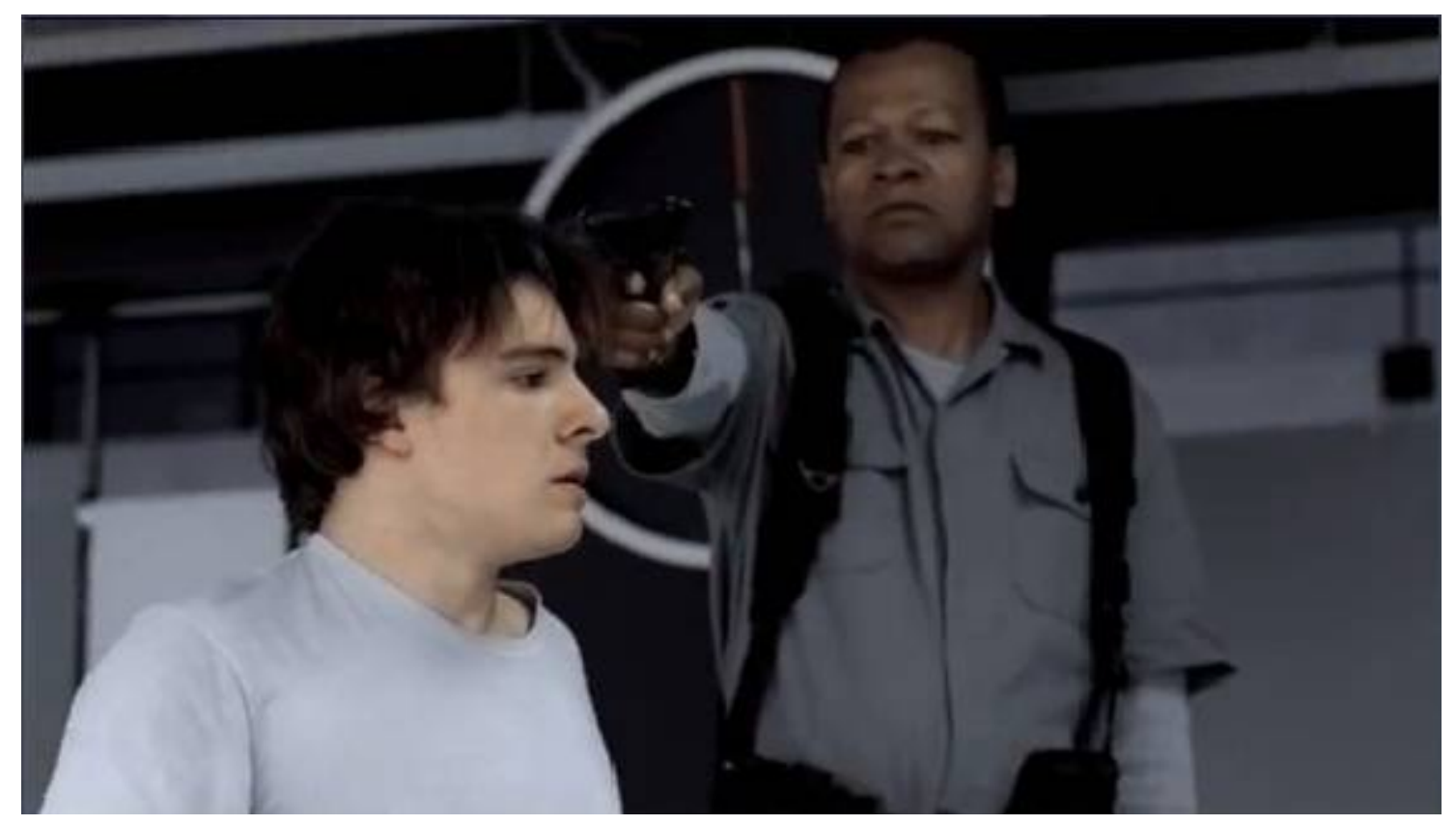

Figura 1 - Cena da webserie 3\%.

Fonte:disponível em:

http://www.youtube.com/watch?v=PwpVnAjb1qU\&feature=BFa\&list=SPF7D1EE3144E33A57

Acesso em 05 abril 2012.

O personagem negro atua aqui como algo que Giroux (1999) diz acerca do discurso midiático sobre o negro nos filmes dos EUA: um burocrata, incapaz de pensar por si mesmo, cumprindo sua função na ordem social. Nesse caso o negro é a corporificação do aparato opressor do Estado, e detém o poder a ele concedido na forma de arma de fogo.

A cena seguinte mostra Tiago na enfermaria. O corpo de Bruna chega coberto por um lençol. Com a narração da personagem, ficamos sabendo que ela foi morta após agredir um dos guardas com uma caneta. A série acaba aqui, por enquanto.

É tão perceptível a escassez de personagem negros na série que, nos créditos finais, em que os atores coadjuvantes são apresentados como "funcionário alto" e "funcionário careca”, o guarda negro é apresentado como “funcionário negro”. Enquanto metáfora para a situação dos jovens diante do mercado de trabalho, $3 \%$ desloca os personagens negros da possibilidade de brigarem por cargos mais altos, uma vez que todos os personagens com status da webserie são brancos. Aqui estamos diante de um momento onde o cômico é evocado, ainda que após a conclusão da narrativa: trata-se de uma banalização conforme proposta por Guareschi (2000) que, ao analisar um programa humorístico, interpretou que esse tratava de maneira cômica certos assuntos de interesse da sociedade como uma forma de tirar o possível poder de contestação deles. Em 3\% interpretamos que o cômico é evocado como uma forma de dizer ao público que os produtores estavam cientes da pouca participação de negros na trama, mas que a crítica não seria considerada relevante. 
Outra webserie é Lado Nix. Essa narra parte da história de uma adolescente, Nix, menina branca de classe média que, sendo criada pelo pai após sua mãe abandonar a família para viver com outro, começou a gostar da cultura nerd. De fato, Lado Nix, roteiro e direção de Paulo Mavu, é uma webserie repleta de referencias a cultura nerd, desde Star Wars ${ }^{7}$ até o Super Mario World ${ }^{8}$.

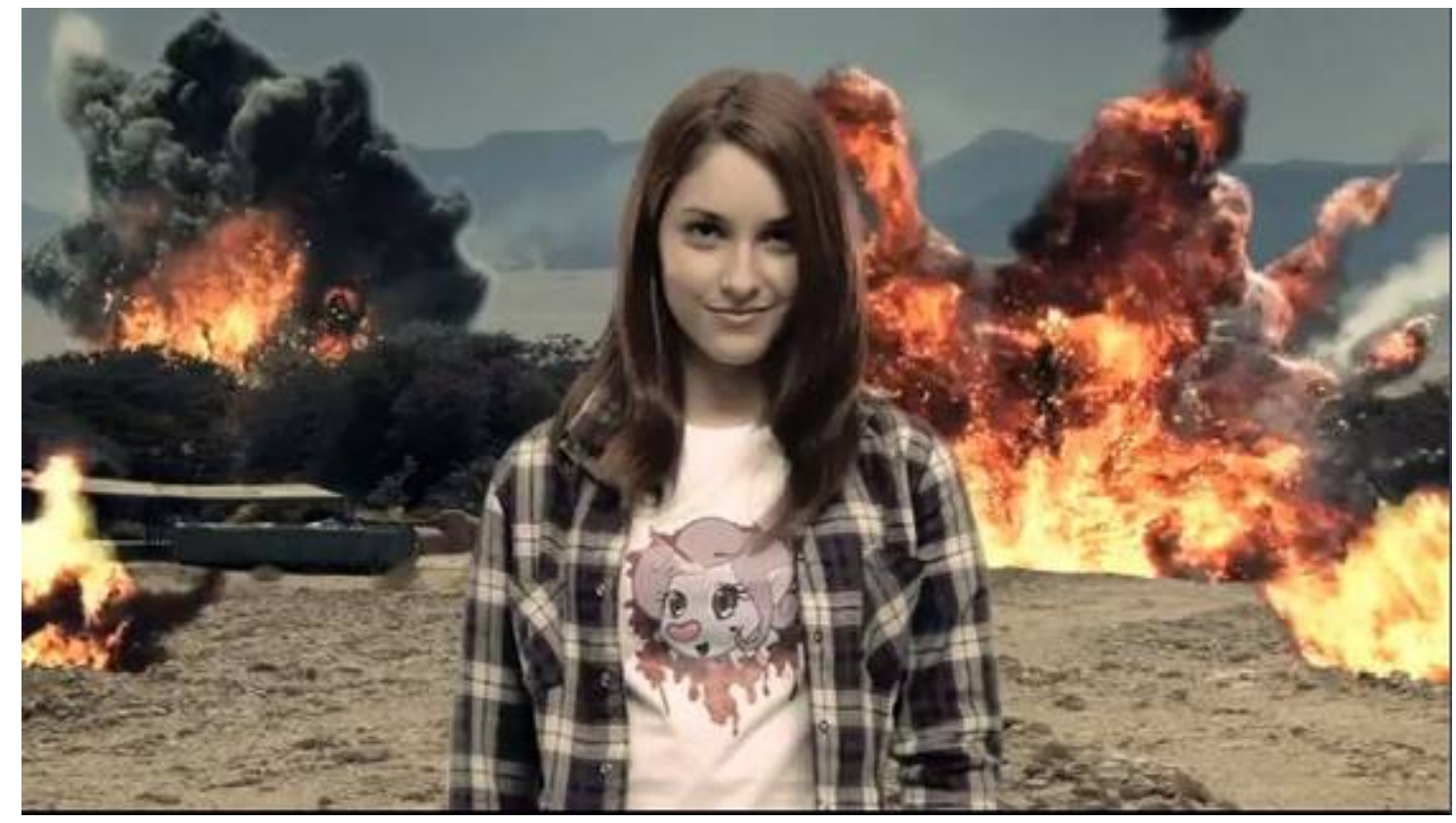

Figura 2 - Cena da webserie Mundo Nix.

Fonte: disponível em: http://www.youtube.com/watch?v=jjgKkVIPPHs Acesso em: Acesso em 05 abril 2012.

Nix é desenhista, e ela e seus amigos (um menino branco e uma menina branca) circulam pelo local de trabalho da jovem, uma banca de revistas em quadrinhos. Os episódios

\footnotetext{
${ }^{7}$ Star Wars ou Guerra nas Estrelas é uma famosa série de filmes de ficção científica de George Lucas.

${ }^{8}$ Super Mario World é o mais conhecido jogo para videogame do personagem Mario, da Nintendo. 
dessa temporada giram em torno do duelo de Nix com sua rival, outra menina branca, que é filha do dono de uma poderosa editora de histórias em quadrinhos. Nix tem uma ligação forte com histórias em quadrinhos, pois além de desenhar sua própria história, seu pai era desenhista. Em todos os episódios dessa temporada, o único personagem negro que aparece é um vendedor de pães que bate a porta de Nix, numa insinuação de que sua mãe traia seu pai com vários homens. Aqui apontamos não apenas para a falta de personagens negros no circulo de amigos de classe média da protagonista Nix (o que contradiz a suposta democracia racial brasileira), que inclui apenas personagens brancos, o que Araújo (2000) descreve como estética ariana; mas também a falta de personagens negros sendo apresentados em situações de família, algo comum na mídia brasileira como apontam estudos de Silva e Rosemberg (2008).

A última webserie que apresentamos aqui é Heróis, dirigida por Guto Aeraphe. Heróis não tem um personagem narrador; o contexto da webserie é apresentado nas legendas que aparecem nos primeiros minutos de exibição. A história é sobre um grupo de soldados brasileiros que lutou na Segunda Guerra mundial em 1944 na Itália.

Ao contrário das outras webseries analisadas, Heróis não conta com muitos diálogos entre os personagens. As cenas de ação ocupam boa parte dos episódios; o primeiro episódio, aliás, começa com os soldados correndo em um campo aberto, desviando de explosões, com armas de fogo, contra a tropa inimiga. O protagonista de Heróis é o próprio grupo de soldados. Cada um deles é chamado apenas pelo primeiro nome ou apelido, como Arlindo, Baeta e Nego. Nego, aliás, é o único personagem negro da webserie. Todos os outros apresentados são brancos. As relações entre Nego e os outros soldados brasileiros ocorrem quase sempre de maneira horizontal, isto é, sem criação de hierarquias, uma das características das relações raciais brasileiras como argumenta Telles (2003).

Os inimigos, brancos alemães, são apresentados como frios e calculistas, assim como os filmes de Guerra estadunidenses via de regra fazem. Em uma cena, Nego é designado a ir para a linha de frente e atacar o inimigo por um flanco, dando a oportunidade para a tropa atacar pelo outro. Ele demonstra medo e se recusa a ir, de inicio. O sargento ordena mais uma vez e ele parte. De faca em punho, Nego ataca o inimigo, mas percebe que ele já está morto. Nervoso com a situação, Nego grita que quer sair daquele lugar (da guerra). O soldado o puxa pelo uniforme e diz: "Tá todo mundo cheio dessa merda, criolo".

Nego é o único personagem racializado do grupo. Além de criolo, ele também é chamado de negão; nesses momentos as relações raciais entre ele e os outros soldados 
brasileiros, que são brancos, ocorre de modo vertical, ou seja, com hierarquização (TELLES, 2003), o que indica que em momentos de competição a raça será evocada para determinar as possibilidades de cada um: é o que acontece quando o soldado grita com Nego, chamando-o de criolo (SANTOS, 1984). Por outro lado, os brasileiros chamam os alemães de branquelos, no sentido pejorativo, o que parece indicar que eles não se reconhecem como brancos. Racialização pode ser, aqui, um modo de fazer a diferenciação, estratégia ideológica descrita por Thompson (1995); estratégia discursiva que utiliza determinadas características dos indivíduos para construir e justificar hierarquias. Se essa diferenciação vale para os inimigos alemães, vale também para Nego: apesar de fazer parte da tropa, sua raça, sua cor, o impede de ser reconhecido como igual - seu apelido evoca sua condição racial. Nego pode ser descrito como o personagem negro que aceita sua racialização no grupo e coloca em risco a própria vida para salvar os brancos.

Na tentativa de salvar um soldado brasileiro, Nego acaba perdendo a vida para um soldado alemão que, pouco depois, confessa ser brasileiro recrutado pelas tropas nazistas por ser descendente de alemães. Essa cena, ao mesmo tempo em que apaga a presença do soldado negro, redime o soldado branco de seu erro. Após a queda de toda a tropa brasileira, esse mesmo soldado enterra os três últimos soldados a cair; três soldados brancos que ele chama de heróis.

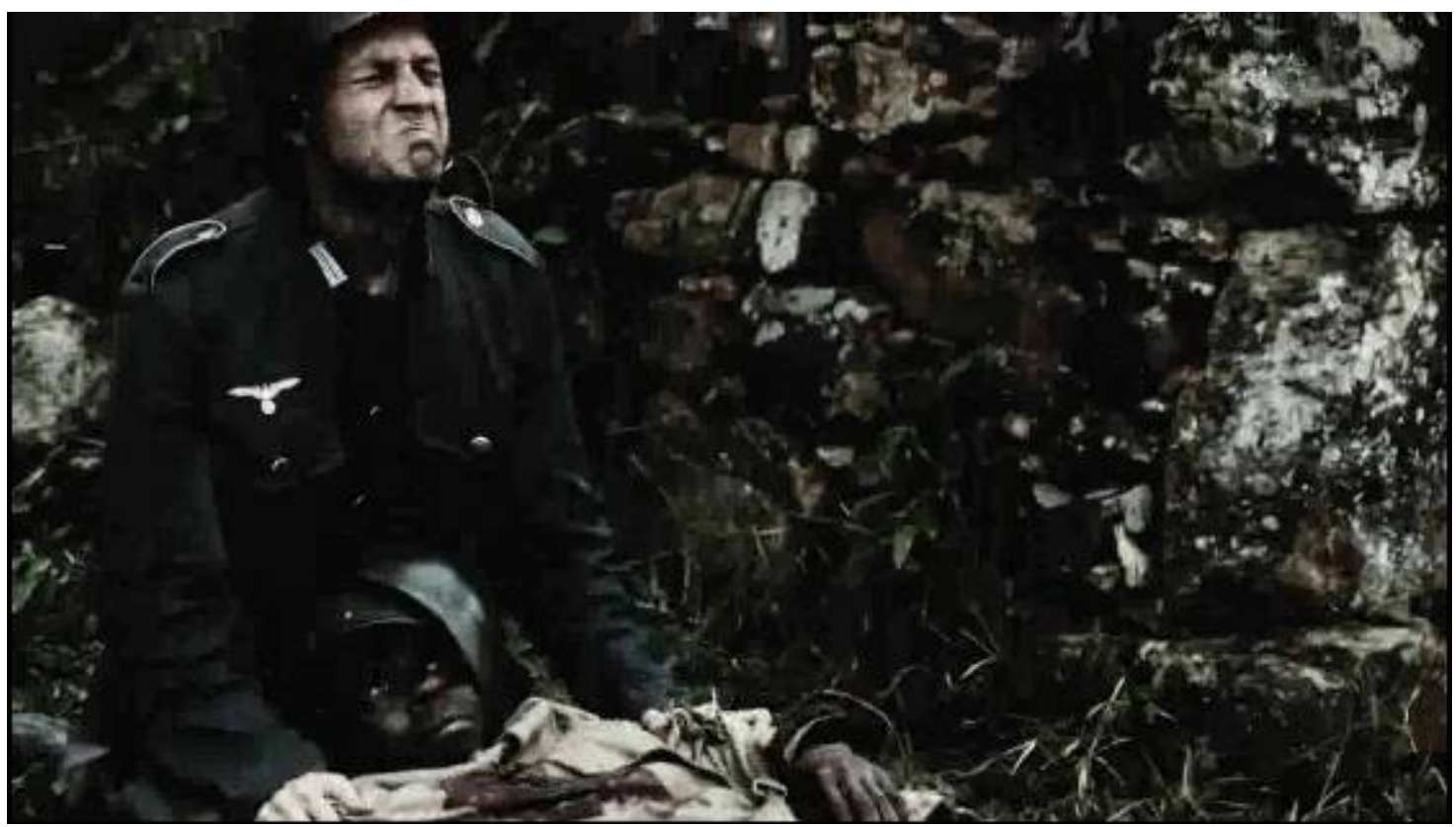

Figura 3 - Cena da webserie Heróis.

Fonte: disponível em: http://www.youtube.com/watch?v=D3a6YLcP-u4 Acesso em 05 abril 2012. 
Nas três webseries que analisamos, além de serem colocados como personagens secundários, os personagens negros aparecem em profissões subalternas. Como argumenta Guimarães (1997), o racismo brasileiro concede aos negros espaços sociais inferiores. Outra constatação é que poucas vezes os rostos dos personagens negros são apresentados de perto pelas câmeras. Ainda que Nego seja o único protagonista negro encontrado nas três webseries, o número de tomadas close-up (isto é, momentos em que a câmera focaliza seu rosto) é menor que o dos outros protagonistas de Heróis. Analisar o close-up é útil para verificar quais personagens estão sendo valorizados, pois de acordo com Roso et al (2002), o close-up serve para uma aproximação entre os personagens e o público, capaz de gerar simpatia e intimidade, algo que tende a ser privilégio dos personagens brancos na mídia nacional. É como se existisse uma impossibilidade de apresentação dos traços do rosto negro. Estamos diante de uma estética ariana (ARAÚJO, 2000) que valoriza os traços dos personagens brancos, mas não dos negros.

Existem estereótipos nas aparições dos personagens negros, com exceção da aparição da mulher negra: o homem negro guarda representa a força e a repreensão. Ao segurar a arma na mão e apontar para os personagens brancos, ele atua de modo a ser o braço armado daqueles que controlam o mundo em que vivem os personagens de 3\%; entretanto, ao contrário dos entrevistadores, ainda que esteja entre aqueles que fazem parte do "lado bom”, ele não desempenha qualquer papel intelectual.

No caso do padeiro negro, ao surgir em uma insinuação das traições da mãe de Nix, surge com o estereótipo do negro hipersensualizado, que faz parte das produções simbólicas brasileiras há anos, segundo Araújo (2000). A apresentação do personagem negro como aquele que deixa o seu posto de trabalho para se aventurar em uma relação sexual parece reforçar o aspecto instintivo. Os negros não seriam capazes de controlar suas paixões e, numa sociedade que valoriza a razão, isso os colocam como seres inferiores.

Já em Heróis, Nego tem muito mais fala no vídeo do que os personagens negros de 3\% e Lado Nix juntos. Ainda que ele seja apresentado também como um braço armado daqueles que controlam o mundo, assim como o guarda negro de 3\%, ele contesta essa situação, ao demonstrar insatisfação por participar de uma guerra que não é sua. Entretanto seu destino é cruel, pois morre justamente pelas mãos de um brasileiro branco. O mesmo brasileiro parece se redimir na cena final, quando concede um enterro aos três soldados brasileiros brancos e os nomeia heróis. 
Quanto aos personagens brancos das três webseries, eles são apresentados como adultos racionais, piedosos, inteligentes, espertos, capazes de decidir entre o bem e o mal, em 3\% e em Heróis, ou com jovens com sonhos, alegrias, incertezas, desilusões, amor, em Lado Nix. Ou seja, ocorre uma apresentação desigual de personagens negros e brancos e uma apresentação desigual de características desses personagens, rumo a uma naturalização dos personagens brancos. Personagens brancos são desenvolvidos durante as narrativas, o que também está relacionado ao espaço que ocupam, via de regra como protagonistas; personagens negros permanecem, via de regra, nos mesmos lugares, o que no atual contexto sócio-histórico, de desigualdades entre negros e brancos no acesso a bens materiais e simbólicos, auxilia na manutenção de hierarquização simbólica entre esses grupos raciais.

\section{CONSIDERAÇÕES FINAIS}

Como apontamos na análise, os negros estão distantes de serem representados de maneira digna, seja em termos quantitativos, seja em termos qualitativos, nessa nova forma de produção simbólica. Considerando que as webseries brasileiras, via de regra, são feitas como episódios pilotos para uma possível transposição para a televisão ${ }^{9}$, elas poderiam significar a oportunidade de mudanças no modo como negros e brancos são tratados pelo discurso da mídia, apresentando mais personagens negros em situações de humanidade plena. Porém, as webseries repetem os discursos de hierarquias raciais que estão presentes tanto na televisão como em outras mídias, tais como televisão, cinema, literatura e livros didáticos (SILVA; ROSEMBERG, 2008).

Defendemos que a proposta de Thompson para análise da ideologia nos meios de comunicação de massa também é pertinente para a análise dos meios de comunicação da chamada por alguns “web 2.0”. Isso porque, por mais que existam diversas relações de poder entre as pessoas, e pelas possibilidades de criação de produtos simbólicos por aqueles que antes eram apenas espectadores, a definição de Thompson (1995) como poder como capacidade de acesso a bens materiais e simbólicos é útil em contextos socio-históricos em que desigualdades permanecem entre grupos de indivíduos, no caso negros e brancos. O conceito de ideologia pode ser utilizado para análise crítica das mídias brasileiras. Ele é útil para se pensar a ideologia da democracia racial: uma ideologia que atua de modo a deixar tudo como está.

\footnotetext{
${ }^{9}$ De acordo com reportagem da revista Época de São Paulo, acesso em 06 de junho de 2012. Disponível em: http://epocasaopaulo.globo.com/cultura/do-drama-a-ficcao-cientifica-oito-webseries-para-ver-no-computador/
} 
Devemos atentar também para análises que não fiquem presas apenas em um grupo racial minoritário (negro ou indígena), mas que explicite as relações existentes entre esses grupos e o grupo dominante, no caso o grupo branco. Agindo assim contribuímos para a desnaturalização das hierarquias raciais.

\section{REFERÊNCIAS}

ANDRADE, Leandro F. Prostituição infanto-juvenil na mídia: estigmatização e ideologia. São Paulo: Editora da PUC - SP (EDUC), 2004.

ARAÚJO, Joel Z. Identidade racial e estereótipos sobre o negro na TV brasileira. In: GUIMARÃES, Antonio S. e HUNTLEY, Lynn (org.). Tirando a máscara: ensaios sobre o racismo no Brasil. São Paulo: Editora Paz e Terra, 2000, p. 77-95.

ARAÚJO, Júlio C; COSTA, Rafael R. A fúria do führer: um estudo das estratégias discursivo-pragmáticas presentes num "viral” do Youtube. Linguagem em (Dis)curso, Tubarão, SC, v. 11, n. 2, p. 283-309, maio/ago. 2011

BRASIL. Estatuto da Igualdade Racial. Lei Federal 12.288 de 20 de julho de 2010.

GIACOMINI, Lívia B. O Reflexo Online das Novas Tecnologias na Comunicação: uma análise de sua inserção política, algumas ferramentas e a problemática da exclusão digital. RELEM - Revista Eletrônica Mutações, janeiro-julho, 2011.

GUARESCHI, Pedrinho A. (Org.). Os construtores da informação: meios de comunicação, ideologia e ética. Petrópolis: Vozes, 2000.

GUIMARÃES, Antônio S. A. Racismo e antirracismo no Brasil. Tese. Universidade de São Paulo, 1997, 248p.

HARVEY, David. A condição pós-moderna: uma pesquisa sobre as origens da mudança cultural. Tradução de Adail Ubirajara Sobral e Maria Stela Gonçalves. São Paulo: Edições Loyola, 1993.

JENKINS, Henry. Cultura da convergência: a colisão entre os velhos e novos meios de comunicação. São Paulo: Aleph, 2009.

MESSA, Márcia R. A cultura desconectada: sitcoms e séries norteamericanas no contexto brasileiro. UNIrevista - Vol. 1, n 3, julho 2006.

ROSO, Adriane; STREY, Marlene N; GUARESCHI, Pedrinho; BUENO, Sandra M. N. Cultura e ideologia: a mídia revelando estereótipos raciais de gênero. Psicologia \& Sociedade; 14 (2): 74-94; jul./dez.2002, p.74-94. 
SANTOS, Everton R. Ideologia e dominação no Brasil (1974-1989): um estudo sobre a Escola Superior de Guerra. Sociedade e Estado, Brasília, v. 22, n. 1, p.153-185, jan./abr 2007.

SANTOS, Joel Rufino dos. O que é racismo. São Paulo: Brasiliense, 1984.

SANTOS, Wellington O.; SILVA, Paulo V. B. Racismo discursivo e a mulher negra: análise a partir dos personagens presentes na publicidade e nos cadernos de saúde de jornais impressos. Revista Theomai (Online), v. 01, p. 161-169, 2010.

SILVA, Paulo V. B. Relações raciais em livros didáticos de língua portuguesa. Tese. Pontifícia Universidade Católica de São Paulo, 2005, 228p.

SILVA, Paulo V. B. Projeto "Racismo e discurso na América Latina": notas sobre personagens negras e brancas no discurso midiático brasileiro. In: III Simpósio Internacional sobre Análise do Discurso. Belo Horizonte, Núcleo de Análise do Discurso (NAD) e o Programa de Pós-Graduação da Faculdade de Letras da Universidade Federal de Minas Gerais, $1^{\circ}$ a 4 de abril de 2008.

SILVA, Paulo V. B.; ROSEMBERG, Fúlvia. Brasil: lugares de negros e brancos na mídia In: VAN DIJK, Teun (Org.). Racismo e Discurso na América Latina. São Paulo: Contexto, 2008.

SILVA, Paulo V. B., SANTOS, Wellington O.; ROCHA, Neli G. Racismo discursivo, legislação e proposições para a televisão pública brasileira In: ARAÚJO, Joel Z. (org.) O negro na TV pública. Brasília: Fundação Cultural Palmares, 2010, v.1, p. 81-112.

TELLES, Edward. Racismo à brasileira: uma nova perspectiva sociológica. Rio de Janeiro: Relume Dumará, 2003.

THOMPSON, John B. Ideologia e cultura moderna: teoria social crítica na era dos meios de comunicação de massa. Petrópolis: Vozes, 1995.

Original recebido em: 05/07/2013

Aceito para a publicação em: 20/07/2013

Resumo do autor:

Wellington Oliveira dos Santos é doutorando em Educação na Universidade Federal do Paraná, Mestre em Educação, Psicólogo. Professor e pesquisador do Núcleo de Estudos Afro-Brasileiros da Universidade Federal do Paraná (NEAB-UFPR). 